\title{
Diretrizes para um Conceito de Serviço Público: necessidade brasileira ou
}

\author{
enclausuramento de uma concepção?
}

Guidelines for a Concept of Public Service: Brazilian need or enclosure framing?

Cláudia R.L. Rentroia ${ }^{1}$

\section{Resumo}

\begin{abstract}
O presente estudo tem como escopo analisar a modificação ocorrida na concepção clássica do conceito de serviço público em função de alteração nas relações jurídicas entre Estado e particulares. Pretende-se colaborar com a reflexão crítica da necessidade de se estabelecer, no Brasil, instrumentos que mais se aperfeiçoem na proteção dos interesses do Estado, mas também do interesse coletivo e social, com nova abrangência do conceito de serviço público.
\end{abstract}

Palavras-Chave: Serviço Público; Conceito; Interesse estatal e social.

\begin{abstract}
The scope of this study is to analyze the changes occurring in the classical conception of the concept of public service in terms of change in legal relations between state and private. The aim is to collaborate with the critical reflection of the need to establish, in Brazil, more instruments to ripen in the protection of state interests, but also the collective and social interest, with new coverage of the concept of public service.
\end{abstract}

Keywords: Public Service. Concept. State and social interest.

\section{Introdução}

O presente estudo tem como escopo analisar a modificação envidada na concepção clássica do conceito de serviço público, a partir da noção surgida na União Europeia, onde novos instrumentos passaram a orientar os operadores do Direito e a sociedade em geral. Classicamente, os requisitos exigidos para a configuração de serviço público se mostravam

1 Mestra em Poder Judiciário da FGV Direito Rio. Pós-graduada em Direito Público pela Universidade Estácio de Sá. Graduada em Direito. Professora de Direito Público de diversas IES no Rio de Janeiro. 
frente ao estreito atuar do Estado no interesse social. Atualmente, porém, devem ser focados numa noção mais ampla de interesse econômico coletivo e integrativo entre povos.

Para o alcance do objetivo proposto, inicialmente são apresentados os posicionamentos de diversos autores pátrios a respeito do tema, visto que não há um consenso a respeito nem mesmo dos elementos característicos do serviço público. Cada doutrinador adota um conceito mais ou menos amplo, abordando variados critérios de composição.

Em seguida são apresentados os conceitos adotados pelos documentos que criaram e que atualmente regem a União Europeia. Tal estudo se justifica, visto que se trata de uma tentativa de unificar entendimentos conflitantes adotados pelos vários Estados que compõem tal organismo supranacional.

Por derradeiro é apresentada a análise realizada pelos Ministros do Supremo Tribunal Federal (STF) na Ação de Descumprimento de Preceito Fundamental (ADPF) $n^{\circ}$ 46/DF, em que se discutiu o enquadramento jurídico da Empresa Brasileira de Correios e Telégrafos (ECT) e, em consequência, o conceito de serviço público a ser adotado no ordenamento pátrio.

Desta forma, pretende-se colaborar com a reflexão crítica da necessidade de se estabelecer, no Brasil, quer na doutrina, quer na teleologia legal, instrumentos que mais se aperfeiçoem na proteção dos interesses do Estado, mas também do interesse coletivo e social, com nova abrangência do conceito de serviço público.

\section{Conceitos de Serviço Público}

Remotamente, a problemática que se vislumbra parece decorrer do fenômeno da globalização como lugar comum das reflexões e causas atuais. Ao que tudo indica, a consequente interatividade entre os diversos Estados em suas relações tem influenciado e praticamente os obrigado a adotar novas concepções nos mais diferentes aspectos e níveis: desde os puramente econômicos até aqueles relativos à proteção dos direitos fundamentais do ser humano. 
Diretrizes para um conceito de Serviço Público: necessidade brasileira ou enclausuramento de uma concepção?

Mais concretamente, no que interessa à discussão proposta sobre a concepção dos serviços públicos - como aqueles prestados pessoalmente pelo poder público² -, não há consenso na doutrina acerca de um conceito absoluto atualmente utilizado por todos os principais doutrinadores. Cada autor constrói seu significante próprio para a locução serviço público, a depender da ênfase em determinado aspecto a ser estudado.

Alexandre Santos de Aragão alerta, inclusive, para a dificuldade em conceituar "um fenômeno tão multifacetado e dinâmico como os serviços públicos" (ARAGÃO, 2007, p. 75). Para o autor, melhor é apresentar-se a 'noção' de serviço público, pois esta permite uma análise mais abrangente das contradições próprias de uma expressão de tal maneira complexa.

A questão, ao que tudo se mostra, não é apenas de ordem conceitual ou filosófica, tanto que também Helga Maria Sabóia Bezerra alerta para a dificuldade em se alcançar um conceito de serviço público, e informa que

[...] as normas jurídicas não esclarecem seu significado e as doutrinas estão repletas de intermináveis tentativas de definição, de modo que há algumas muito amplas e outras muito reduzidas, dependendo do autor que as tenha descrito, do tempo e da situação espacial a que se referem, isto é, em que ordenamento jurídico, de que determinado Estado. (BEZERRA, 2008, p. 104-105.)

Sabidamente, esta dificuldade ou pouco clara nuance de se precisar o conceito em desafio, ou ao menos vê-lo abranger-se de seus limites tradicionais de significação, implica deduzir questões práticas (como mais adiante se mostrará), e não somente de se limitar a um empreendimento de aspecto filosófico ou morfológico. A ampliação do conceito faz com que não apenas novos elementos sejam trazidos, mas, por consequência, novos dados objetivos sejam acrescidos, aumentando-se, por sua vez, os constructos capazes de indicar possíveis conflitos. Permite, ainda, a análise de novos fatos jurídicos de interesse do estudo da administração pública, antes não envolvidos por falta destes elementos de maior abrangência conceitual.

2 Esta era a concepção adotada pela Escola do Serviço Público ou Escola de Bordeaux, no início do século XX, cujos representantes iniciais foram os franceses Leon Duguit e Gaston Jèze. Odete Medauar (2008, p. 314), chama a atenção para o fato de falar-se em crise da noção de serviço público quando em decorrência do aumento das prestações estatais e da variedade com que se passou a prestá-las, inclusive por particulares, tal conceito inicialmente adotado passou a não mais refletir a realidade. Segundo a autora, porém, a "atividade de prestação de serviços públicos não se encontra em crise, nem desapareceu; ao contrário, hoje se reveste de grande importância". 
Já Hely Lopes Meirelles (2009, p. 332), em seus ensinamentos, afirmava que o conceito de serviço público:

[...] ora nos oferece uma noção orgânica, só considerando como tal o que é prestado por órgãos públicos; ora nos apresenta uma conceituação formal, tendente a identificá-lo por características extrínsecas; ora nos expõe um conceito material, visando a defini-lo por seu objeto.

Serviço público, para o mestre Hely (2009, p. 332), seria "todo aquele prestado pela Administração ou por seus delegados, sob normas e controles estatais, para satisfazer necessidades essenciais ou secundárias da coletividade ou simples conveniências do Estado". Assim, não se poderia levar em consideração as atividades exercidas para se chegar a um conceito, visto que cada sociedade elegeria aquelas que, em determinados momentos históricos, Ihe são fundamentais. Também não se pode adotá-las como base para um conceito, pois algumas são exercidas pelo Estado, enquanto outras o são pela iniciativa privada ${ }^{3}$. Poder-se-ia considerar, então, as chamadas "atividades coletivas vitais", porém o próprio autor chama a atenção para o fato de que muitas delas poderiam ser consideradas dispensáveis por determinada sociedade e, ainda assim, serem prestadas pelo Estado ${ }^{4}$.

Desta forma, ante o enquadramento que se possa atribuir à conceituação de Hely, ao que se mostra, sua classificação decorre de uma noção orgânica, quando faz aliar a origem (funcional) de onde promana a uma finalidade de natureza estamental.

Por sua vez, Maria Sylvia Zanella Di Pietro (2010, p. 102), em oposição às colocações de Hely Lopes Meirelles, considera o critério material, ou seja, o da atividade, como fundamental para a conceituação de serviço público. Segundo a autora, serviço público é:

toda atividade material que a lei atribui ao Estado para que a exerça diretamente ou por meio de seus delegados, com o objetivo de satisfazer concretamente às necessidades coletivas, sob regime jurídico total ou parcialmente público.

3 É o caso, mencionado por Meirelles, do ensino, em que haverá serviço público quando prestado pelo Estado. Quando prestado pelos cidadãos, por sua vez, assim não serão caracterizados.

4 Os exemplos mencionados por Hely Lopes Meirelles são esclarecedores: Cassinos em Monte Carlo, no Principado de Mônaco e Loteria Esportiva e Federal no Brasil. Trata-se de atividades prestadas pelo Estado, mas dispensáveis pela sociedade, que não as consideram vitais e, portanto, como elementos que poderiam caracterizar um serviço como público. 
Diretrizes para um conceito de Serviço Público: necessidade brasileira ou enclausuramento de uma concepção?

A autora também concorda com a dificuldade em se definir a expressão serviço público, não só pela sua evolução no transcorrer do tempo, como também pelo fato de haver a possibilidade de se considerar um conceito amplo ou um conceito mais restrito (DI PIETRO, 2010, p. 98). Não cumpre o objetivo pretendido por este estudo adentrar nos meandros do conceito discutidos pela autora em sua obra, visto que o que se visa é demonstrar as controvérsias e as problemáticas que envolvem a expressão.

É importante salientar, no entanto, que Di Pietro menciona as chamadas "crises na noção de serviço público". Primeiramente faz referência à crise ocorrida em meados do século $X X$, que alterou os critérios definidores de serviço público e, por conseguinte, o conceito até então adotado.

Para a autora (DI PIETRO, 2010, p. 100), em seus primórdios serviço público era definido: (i) segundo um critério subjetivo, ou seja, pela presença do Estado como pessoa jurídica prestadora de tais serviços; (ii) segundo um critério material, em que seria considerado serviço público a atividade que visasse a satisfação de necessidades coletivas; (iii) e, ainda, segundo um critério formal, onde "serviço público seria aquele exercido sob regime de direito público derrogatório e exorbitante do direito comum".

Segundo Di Pietro, durante o liberalismo a combinação desses critérios serviu como base ao conceito de serviço público. Porém, com o aumento das atividades estatais próprias e com a constatação da incapacidade do Estado de prestar, por seus agentes, tais atividades, tanto o critério subjetivo quanto o critério formal foram profundamente afetados. O primeiro porque, atualmente, o Estado não é a única pessoa a prestar tais serviços e o segundo pelo fato de não se vislumbrar mais somente um regime exclusivamente público.

Uma segunda "crise na noção de serviço público" mencionada pela doutrinadora (DI PIETRO, 2010, p. 105) surge com o Tratado de Roma, em 1957, que instituiu a Comunidade Econômica Europeia (CEE), posteriormente substituída e sucedida pela União Europeia. O Tratado, inclusive, não faz menção à expressão 'serviço público' e sim a 'serviço de interesse econômico geral'. A autora (DI PIETRO, 2010, p. 105) esclarece por que se voltou a falar em nova crise:

Embora de início não houvesse oposição a que os Estados-membros mantivessem os seus conceitos tradicionais de serviço público e os monopólios estatais, a partir da década de 80 houve um entendimento mais rígido, que implicou confronto com 
o conceito de serviço público oriundo do direito francês. A consequência foi a sucessiva liberalização e privatização dos serviços públicos tradicionais.

Di Pietro, no entanto, não vislumbra a possibilidade de se falar, no Brasil, em crise do conceito de serviço público tradicionalmente adotado. Justifica seu posicionamento com base na existência de dispositivos constitucionais adotando tal conceito ${ }^{5}$. Logo, somente seria possível adotar outro entendimento mediante a alteração da Constituição da República Federativa Brasileira atual (CRFB/88) (DI PIETRO, 2010, p. 106-107).

Por outro lado, a existência do que se possa denominar "crise da noção de serviço público" é contestada por Dinorá Adelaide Musetti Grotti (2003, p. 53), que esclarece que o "tema da crise começou a se delinear com a alteração dos elementos integrantes da noção que originalmente se propôs do serviço público", mas adverte que ao lado de alguns defensores de sua existência há outros que não a admitem. Como exemplos daqueles que defendem a crise, a autora menciona Jean-Louis de Corail (apud Grotti, 2003, p. 56), que afirma que "a noção de serviço público não tem mais valor jurídico", e Eisenmann (apud Grotti, 2003, p. 56 e 57), que acredita que tal noção deve ser "relegada ao plano da história do direito administrativo".

Não obstante, apresenta aqueles para os quais o que há, verdadeiramente, é a evolução do conceito de serviço público e não uma "crise". Esclarece que "Marienhoff também acredita que a crise, entendida como quebra ou falência do conceito, não existe. Todavia, se se concluir que a crise corresponde a uma evolução conceitual dos elementos que integram a noção, à crise dever-se-á chamar evolução" (GROTTI, 2003, p. 58). Para a autora (GROTTI, 2003, p. 60), portanto, há "um declínio da noção tradicional que passou a mostrar-se em dissonância com a realidade", mas que "a chamada crise refletia apenas a inadequação de uma teoria específica à extensão das prestações estatais, realizadas sob modos muito variados".

Pela sua abrangência e em função do objetivo proposto para o presente estudo, as divergências entre os pensamentos dos diversos autores pátrios e estrangeiros a respeito da existência ou não de uma crise da noção de serviço público não serão objetos de enfrentamento aprofundado. Pretende-se aqui, apenas, a apresentação dos vários enfoques abordados pelos diversos autores em relação ao conceito de serviço público.

5 Como é o caso, por exemplo, do art. 21. 
Diretrizes para um conceito de Serviço Público: necessidade brasileira ou enclausuramento de uma concepção?

José dos Santos Carvalho Filho $(2009$, p. 307) também reconhece a dificuldade em conceituar serviço público, em função dos variados elementos que compõem tal conceito. Afirma o autor que o conceito aceitável é aquele que se alcança com a inclusão dos vários critérios relacionados à atividade pública. Leciona que serviço público deve ser entendido como "toda atividade prestada pelo Estado ou por seus delegados, basicamente sob regime de direito público, com vistas à satisfação de necessidades essenciais e secundárias da coletividade" (CARVALHO FILHO, 2009, p. 307).

Odete Medauar (2008, p. 314), por seu turno, evita apresentar um conceito hermético da expressão, preferindo analisar os vários elementos que a caracterizam. Segundo a autora, "o serviço público apresenta-se como uma dentre as múltiplas atividades desempenhadas pela Administração, que deve utilizar seus poderes, bens e agentes, seus atos e contratos para realizá-lo de modo eficiente". Esclarece que ocorreu um retorno à discussão a respeito desse tema em decorrência dos "tratados e documentos da União Européia" (MEDAUAR, 2008, p. 315) existência de serviço público e da "titularidade estatal de atividades" (MEDAUAR, 2008, p. 315).

Marçal Justen Filho (2008, p. 566) esclarece que o conceito adotado no Brasil é mais restrito que aquele desenvolvido na França. O autor apresenta um entendimento mais abrangente a respeito:

Serviço público é uma atividade pública administrativa de satisfação concreta de necessidades individuais ou transindividuais, materiais ou imateriais, vinculadas diretamente a um direito fundamental, destinada a pessoas indeterminadas, qualificada legislativamente e executada sob regime de direito público.

Afirma, em posição diversa à apresentada por Odete Medauar, que várias e seguidas foram as crises do serviço público havendo, inclusive, aqueles que mencionam sua morte (ORTIZ apud JUSTEN FILHO, 2008, p. 583). Dentre outras, Justen Filho apresenta como causa de uma delas as "inovações derivadas da evolução da União Européia" (ORTIZ apud JUSTEN FILHO, 2008, p. 584). Para o autor (ORTIZ apud JUSTEN FILHO, 2008, p. 585), "a distinção entre os regimes jurídicos de atividade econômica privada e serviço público" foi

A autora chama a atenção para o fato de que, nestes textos, "outras expressões vêm sendo mencionadas para atividades classicamente consideradas serviços públicos, como, por exemplo, atividades econômicas de interesse geral, serviços universais, serviços de utilidade pública". 
mitigada, acarretando o surgimento de "um regime jurídico anômalo". E a tendência seria a multiplicação desses regimes jurídicos para que as necessidades coletivas sejam satisfeitas.

\section{0 serviço publico e a União Europeia}

Em um mundo em constante mutação - em seus mais variados aspectos: tecnológico, social e ambiental, por exemplo - surge, logo após o término da Segunda Guerra Mundial, a necessidade e a vontade do enfrentamento conjunto dos novos desafios que se apresentam aos Estados. Tais questões deixam de respeitar as fronteiras geográficas impostas pelo homem e passam a ser preocupações constantes de todos os povos.

Diante dessa globalização são criados vários "blocos" de interesses, dentre os quais a União Europeia ${ }^{7}$, que particularmente interessa para o alcance do objetivo do presente estudo.

Neste sentido, tem-se a contribuição de Dinorá Grotti. A autora identifica uma das causas do que hoje se chama, por corolário, globalização, surgida como necessidade econômica de integração. Assim, esclarece (GROTTI, 2003, p. 73):

Finda a Segunda Guerra Mundial, os países europeus, debilitados pelas duas grandes guerras e impulsionados pela necessidade de evitar novos conflitos, buscaram estabelecer bases concretas para uma efetiva integração européia, de base supranacional.

Em função da criação de tais entidades, de status superior aos de seus Estadosmembros, imperioso se torna o esclarecimento, tanto quanto possível, das expressões e termos usados em seus documentos conjuntos - os tratados internacionais em sentido

\footnotetext{
Na verdade, o processo de integração europeia se iniciou com a assinatura do Tratado de Paris em 1950 (que instituiu a Comunidade Europeia do Carvão e do Aço), seguido do Tratado de Roma em 1957 (criou a Comunidade Económica Europeia). Outros documentos que se seguiram: Ato Único em 1986 (criação do Mercado Único Europeu), o Tratado de Maastricht ou Tratado da União Europeia (TUE) em 1992, o Tratado de Amsterdam em 1999, o Tratado de Nice em 2001 (altera o Tratado da União Europeia e o Tratado que institui a Comunidade Europeia) e o Tratado de Lisboa em 2007 (altera os Tratados da EU - visa melhorar o funcionamento das instituições e os métodos de trabalho da União Europeia), mas que entrou em vigor em 01/12/2009. Fonte: EUROPA. O portal oficial da União Europeia, disponível no endereço http://europa.eu/index_pt.htm. Acesso em 03/01/2011. A pesquisa foi realizada na língua portuguesa.
} 
Diretrizes para um conceito de Serviço Público: necessidade brasileira ou enclausuramento de uma concepção?

amplo. Diante dessa necessidade, cria-se, no âmbito da União Europeia, um glossário que acompanha os tratados e se encontra em constante atualização ${ }^{8}$.

Faz parte ainda dos documentos que regem o atuar dos Estados que compõem a União Europeia a chamada Carta dos Direitos Fundamentais, documento cuja redação foi iniciada em 1998, "no intuito de reunir os direitos fundamentais, em vigor na União, num único texto e de os dotar de uma maior relevância" ${ }^{\prime 9}$ e tem por base não somente os Tratados Comunitários e as convenções internacionais, mas também a Convenção Europeia para a Proteção dos Direitos do Homem de 1950 e a Carta Social Europeia de 1989. Além disso, a Carta dos Direitos Humanos se baseia "nas tradições constitucionais comuns dos Estados-Membros e nas diferentes declarações do Parlamento Europeu"10 ${ }^{\prime 10}$ artigo 36ㅇ da Carta dos Direitos Fundamentais ${ }^{11}$ dispõe a respeito do acesso aos serviços de interesse econômico geral.

Como anteriormente mencionado, na legislação comunitária ${ }^{12}$ não se encontra a expressão ‘serviço público'. No glossário, no entanto, há menção e esclarecimento a respeito do que se espera da atividade prestada à coletividade no âmbito da comunidade formada pelos Estados que aderem aos tratados.

A noção de serviço público tem um duplo sentido, designando tanto o organismo de produção do serviço como a missão de interesse geral a este confiado. É com o objectivo de favorecer ou de permitir a realização de missões de interesse geral que a autoridade pública pode impor obrigações específicas de serviço público a um organismo de produção do serviço, por exemplo, em matéria de transportes terrestres, aéreos ou ferroviários ou em matéria de energia. Estas obrigações podem ser impostas à escala nacional ou regional. Note-se que, com conômico, se confunde erroneamente serviço público e sector público (incluindo a função pública), ou seja, a missão e o estatuto, o destinatário e o proprietário. ${ }^{13}$

8 Para acompanhamento de tais atualizações é possível acessar o portal oficial da União Europeia, no endereço: http://europa.eu/legislation_summaries/glossary/index_pt.htm

9 Glossário da legislação da União Europeia. Disponível no endereço: http://europa.eu/legislation_summaries/glossary/charter_fundamental_rights_pt.htm. Acesso em 03/01/2011. A pesquisa foi realizada na língua portuguesa.

10 Ibidem.

11 Tratados Consolidados e Carta dos Direitos Fundamentais. Disponível no endereço: http://bookshop.europa.eu/is-bin/INTERSHOP.enfinity/WFS/EU-Bookshop-Site/pt_PT/-

/EUR/ViewPublication-Start?PublicationKey=QC3209190. Acesso em 03/01/2011. A pesquisa foi realizada na língua portuguesa. In verbis: "A União reconhece e respeita o acesso a serviços de interesse económico geral tal como previsto nas legislações e práticas nacionais, de acordo com os Tratados, a fim de promover a coesão social e territorial da União".

12 Ou seja, referente à União Europeia.

13 Fonte: EUROPA. O portal oficial da União Europeia, disponível no endereço http://europa.eu/index_pt.htm. Acesso em 03/01/2011. A pesquisa foi realizada na língua portuguesa. 
$\mathrm{O}$ antigo artigo 16 TCE, introduzido pelo Tratado de Amsterdam, consagrou a prestação dos serviços públicos no âmbito da União Europeia. Na versão consolidada do Tratado sobre o funcionamento da União Europeia (artigo 14으, ex-artigo 16ㅇ TCE) ${ }^{14}$, é encontrado o esclarecimento a respeito do que se espera da atuação dos Estados-membros em relação a tais serviços, com o objetivo de promover sua coesão social e territorial. São previstos, ainda, determinados princípios a serem observados para o cumprimento desse objetivo. Como se vislumbra, tal dispositivo menciona a expressão "serviços de interesse econômico geral" que no glossário surge com a seguinte explicação:

Os serviços de interesse económico geral designam as actividades de serviço comercial que preenchem missões de interesse geral, estando, por conseguinte, sujeitas a obrigações específicas de serviço público (artigo 86. - ex-artigo 90. - do Tratado CE). É o caso, em especial, dos serviços em rede de transportes, de energia e de comunicações. ${ }^{15}$

Não se restringe, porém, o glossário, a explicitar tal expressão. Menciona, para completo esclarecimento e orientação, o que se deve entender por serviço universal e serviço de interesse geral.

Serviço universal deve ser compreendido como "um conjunto de exigências de interesse geral a que devem obedecer, em toda a Comunidade, as actividades de telecomunicações ou de correio, por exemplo"16. As obrigações decorrentes do cumprimento de tais exigências visam garantir o amplo acesso "de todas as pessoas a determinadas prestações essenciais de qualidade e a um preço abordável"17.

Por sua vez, por serviço de interesse geral "entendem-se as actividades de serviço, comercial ou não, consideradas de interesse geral pelas autoridades públicas, estando, por

14 Ibidem. In verbis: "Sem prejuízo do disposto no artigo $4 .^{\circ}$ do Tratado da União Europeia e nos artigos 93. $106 .^{\circ}$ e $107 .^{\circ}$ do presente Tratado, e atendendo à posição que os serviços de interesse económico geral ocupam no conjunto dos valores comuns da União e ao papel que desempenham na promoção da coesão social e territorial, a União e os seus Estados-Membros, dentro do limite das respectivas competências e no âmbito de aplicação dos Tratados, zelarão por que esses serviços funcionem com base em princípios e em condições, nomeadamente económicas e financeiras, que lhes permitam cumprir as suas missões. 0 Parlamento Europeu e o Conselho, por meio de regulamentos adoptados de acordo com o processo legislativo ordinário, estabelecem esses princípios e definem essas condições, sem prejuízo da competência dos Estados-Membros para, na observância dos Tratados, prestar, mandar executar e financiar esses serviços."

15 Ibidem.

16 Ibidem.

17 Ibidem. 
Diretrizes para um conceito de Serviço Público: necessidade brasileira ou enclausuramento de uma concepção?

conseguinte, sujeitas a obrigações específicas de serviço público" ${ }^{18}$. Tais serviços comportam uma subdivisão em que se verificam as atividades de serviço não econômico - como, por exemplo, o sistema de escolaridade obrigatória -, as funções intrínsecas à própria soberania - como, por exemplo, segurança e justiça - e, por fim, os serviços de interesse econômico geral - como, por exemplo, os serviços de telecomunicações.

Como anteriormente mencionado, busca-se prestar serviços de qualidade e a preços que permitam o acesso universal a tais serviços. Desde 2003 os Estados-membros têm debatido a respeito do "papel da União Europeia na promoção do fornecimento de serviços de interesse geral, na definição dos seus objectivos de interesse geral e sobre a forma como estes estão organizados, financiados e avaliados" ${ }^{19}$, não chegando, pelo menos até o momento, a um documento com caráter cogente.

Não se pode deixar de mencionar a existência da ideia de elaboração de uma carta dos serviços públicos cujo texto se destinaria a prever e definir os "direitos fundamentais e os princípios que regem a prestação de serviços aos utilizadores", dentre os quais se pode mencionar: a continuidade do serviço, a qualidade, segurança do abastecimento, a igualdade de acesso, um preço razoável e a aceitabilidade social, cultural e ambiental ${ }^{20}$.

\section{0 serviço público e o Supremo Tribunal Federal}

No ordenamento jurídico brasileiro não há discussões legislativas ou administrativas a respeito de um sentido a ser adotado para a expressão serviços públicos. Cabe então ao Poder Judiciário interpretar os dispositivos existentes conferindo à expressão sentido constitucional.

Instado a se manifestar na arguição de descumprimento de preceito fundamental (ADPF) $n^{\circ}$ 46/DF (BRASIL. SUPREMO TRIBUNAL FEDERAL, 2009) - em que foi discutido o privilégio de entrega de correspondências e o serviço postal -, o Supremo Tribunal Federal (STF), órgão máximo do Poder Judiciário e intérprete da CRFB/88, ponderou a respeito de várias questões.

Na ementa da mencionada arguição, os Ministros, por maioria, dispuseram que a atividade econômica em sentido amplo é gênero do qual são espécies a atividade econômica

\footnotetext{
Ibidem.

Ibidem.

20 Ibidem.
} 
em sentido estrito e o serviço público. Em tais atividades se vislumbram dois institutos muito próximos: monopólio e exclusividade. Para as atividades econômicas em sentido estrito, empreendidas tanto por agentes privados quanto pelo Estado, fala-se em monopólio. Por outro lado, para o serviço público, é imprescindível a garantia da exclusividade, entendida essa como uma situação de privilégio.

Em voto vencido, o Ministro Marco Aurélio, analisando a questão interpretativa, alerta para o fato de que ao Supremo cabe, ao interpretar as normas constitucionais, realizar o que se convencionou chamar de mutação constitucional, ou seja, deve harmonizar a norma constitucional escrita "com os demais valores constitucionalmente protegidos - livre iniciativa, livre concorrência, livre exercício de qualquer trabalho e livre exercício de qualquer atividade econômica -, de maneira a garantir a força normativa da Constituição" (BRASIL. SUPREMO TRIBUNAL FEDERAL, 2009). Tal harmonização não significa manter um pensamento estático e vinculativo, ao contrário, interpretações aceitas e que fizeram sentido no passado não se tornam obrigatórias e imutáveis e devem ser repensadas todas as vezes em que possa ocorrer uma mudança de exigência por parte da sociedade. Isso significa que é preciso sempre fazer da realidade hodierna da sociedade brasileira ponto de partida para a interpretação.

Neste sentido, e em relação ao âmbito do presente estudo, alerta o Ministro que distinguir atividade econômica e serviço público não decorre da natureza das coisas e sim de "uma diferenciação historicamente determinada" (BRASIL. SUPREMO TRIBUNAL FEDERAL, 2009).

Em decorrência da evolução do Estado e do consequente aumento de suas funções, não se pode mais admitir um Estado prestacional, ou seja, não se espera que o Estado, por si mesmo, preste, nos dias atuais, todos os assim considerados no passado 'serviços públicos'. Ao contrário, ao Estado deve ser reservada a garantia dos direitos fundamentais e a efetivação dos serviços públicos. E tal reserva não implica, necessariamente, na existência de um Estado interventor e sim de um Estado que atue subsidiariamente, que assegure condições satisfatórias para "o crescimento da economia e o melhor desenvolvimento das capacidades de cada indivíduo, garantindo igualdade de oportunidades e viabilizando os deveres de continuidade, de universalidade e de eficiência na obtenção dos serviços públicos" (BRASIL. SUPREMO TRIBUNAL FEDERAL, 2009). 
Diretrizes para um conceito de Serviço Público: necessidade brasileira ou enclausuramento de uma concepção?

Ou seja, o progresso e o consequente aumento da demanda por bens e serviços melhores e mais acessíveis exige que o Estado se torne fiscalizador das atividades e não mais prestador de serviços.

Para tanto, torna-se necessária uma mudança de mentalidade e de estruturação de sua 'máquina'. A criação de órgãos fiscalizadores autônomos e sem subordinação não basta; é necessário que tais setores se tornem efetivos em suas atividades. A transferência do exercício das atividades antes consideradas estatais para o particular deve ser acompanhada de efetiva fiscalização, sob pena de falência da própria sociedade.

A respeito menciona o Ministro (BRASIL. SUPREMO TRIBUNAL FEDERAL, 2009) em seu voto que:

\begin{abstract}
A ingerência estatal termina por ser mais forte e mais eficaz quando não é o próprio Estado quem presta diretamente o serviço. A influência sobre a gestão privada, em se tratando de eficiência, tornou-se maior após as privatizações do que quando o Poder Público prestava diretamente, ou por intermédio de empresas estatais, os serviços públicos, de forma que, hoje, melhores resultados são alcançados.
\end{abstract}

Inicia, neste momento, o questionamento a respeito do que é e de como deve ser prestado, atualmente, o já desgastado 'serviço público'. O Estado transfere à iniciativa privada a prestação das atividades econômicas por meio da criação de novas figuras jurídicas tais "como a regulamentação dos contratos de concessão e de permissão, os contratos de gestão, os órgãos reguladores, as organizações sociais, as organizações da sociedade civil sem fins lucrativos - Oscips, as agências executivas, as parcerias público-privadas" (BRASIL. SUPREMO TRIBUNAL FEDERAL, 2009).

Ainda em seu voto, o Ministro leciona que não se pode, sob a justificativa de conceituação, permanecer imóvel diante das mudanças e necessidades da sociedade. Necessário se faz, nos dias presentes, verificar qual a atividade que está sendo exercida, analisá-la minuciosamente e, a partir daí, determinar o regime jurídico (público ou privado) a ser observado.

Enfrentando a discussão a respeito do que se deve entender como serviço público o Ministro (BRASIL. SUPREMO TRIBUNAL FEDERAL, 2009) esclarece que: 
No Brasil, a história é pródiga em demonstrar exemplos de que a melhor noção de serviço público não se vincula à essência do objeto em si, mas decorre de uma necessidade pontual e historicamente determinada de maior intervenção a ser feita pelo Estado em certa esfera da economia. O que em época de que não se tem saudade seria facilmente compreendido como "serviço público", a demandar a intervenção estatal, hoje não passaria de manifesta demonstração de interferência indevida do ente público na atividade privada.

Continua sua preleção a respeito do tema informando "que a noção de serviço público não está ligada a questões ontológicas, nem mesmo funciona como corolário da natureza das coisas. Nenhuma atividade é em si mesma, um serviço público" (BRASIL. SUPREMO TRIBUNAL FEDERAL, 2009). Portanto, o grau de intervenção do Estado na atividade econômica é que irá determina sua natureza jurídica. Alerta, ainda, o Ministro Marco Aurélio (BRASIL. SUPREMO TRIBUNAL FEDERAL, 2009):

É preciso não perder de vista a advertência feita por Fernando Herren Aguillar sobre o fato de as correntes definições sobre serviço remeterem a generalizações que foram ganhando espaço ao longo do tempo, de forma que o intérprete termina por filiar-se a longínquas tradições que são reproduzidas, sem proceder, contudo, à indispensável crítica. A par desse aspecto, o uso abusivo do conceito termina por enfraquecer-lhe a importância, banalizando-o e tornando-o carente de significado e de conteúdo.

Iniciando divergência ao posicionamento do Ministro Marco Aurélio, o Ministro Eros Grau afirma, categoricamente, a existência de "serviços públicos por definição constitucional" (BRASIL. SUPREMO TRIBUNAL FEDERAL, 2009) em que a própria Carta identifica e classifica algumas atividades como tais. Logo, segundo o ilustre Magistrado, para que determinadas atividades não sejam consideradas serviços públicos é necessário que a própria CRFB permita sua livre execução pela iniciativa privada. Em sua preleção argumenta que "o serviço público está para o Estado assim como a atividade econômica em sentido estrito está para o setor privado" (BRASIL. SUPREMO TRIBUNAL FEDERAL, 2009).

Leciona o Ministro Eros Grau, ainda em contraste com os argumentos do Ministro Marco Aurélio, que os arts. 1ำ e 3으 da CRFB/88 exigem "um Estado forte, vigoroso, capaz de assegurar a todos existência digna. A proposta de substituição do Estado pela sociedade civil, vale dizer, pelo mercado, é incompatível com a Constituição do Brasil e certamente não nos conduzirá a um bom destino" (BRASIL. SUPREMO TRIBUNAL FEDERAL, 2009). 
Diretrizes para um conceito de Serviço Público: necessidade brasileira ou enclausuramento de uma concepção?

Para o Ministro Joaquim Barbosa, em consonância com a posição adotada pelo Ministro Eros Grau, o Estado detém a titularidade do serviço público e, portanto, "pode delegar sua execução a terceiros, preservando sempre seu poder de regulação" e deve prestá-lo "para atender às necessidades e interesses de toda a coletividade, em todo o território nacional" (BRASIL. SUPREMO TRIBUNAL FEDERAL, 2009).

Já a Ministra Helen Gracie alerta para o fato da existência de determinados serviços públicos - como o são os serviços de saúde e educação - que "são abertos à iniciativa privada, sem concessão ou permissão", afastando, assim, a vinculação do conceito de serviço público unicamente à pessoa que o presta - no caso, o Estado.

Como se verifica, nem mesmo os membros do Supremo Tribunal Federal possuem um posicionamento isento de dúvidas a respeito do conceito de serviço público. A discussão foi ampla e a decisão tomada por maioria de votos.

Enfim, buscados supedâneos no excerto do Pretório Excelso, vê-se, nas palavras do Ministro Marco Aurélio, que a questão da abrangência do que se possa ter por presença do Estado no papel de algumas atividades, torna-as, pela atuação e interesse que se protege, de tipificação lato sensu de serviço público.

A decisão chama a atenção, por fim, de que a classificação não decorre da análise meramente ontológica, mas, como se viu acima, no texto que se descortina apresentar, da finalidade que busca atingir e produzir efeitos.

\section{Conclusão}

Procurou-se demonstrar com o presente estudo a necessidade da criação no ordenamento jurídico pátrio de diretrizes a serem seguidas com o objetivo de se garantir à sociedade brasileira a efetivação de determinados direitos fundamentais do homem. Não se pretendeu, por óbvio, contribuir para o término das discussões a respeito do conceito de serviços públicos. Tal desiderato já foi ensaiado por doutrinadores de reconhecimento nacional e internacional e não foi alcançado.

Pretendeu-se, contudo, a demonstração da necessidade de criação de um documento - chamado pelos tratados internacionais constituidores da União Europeia de Carta dos Serviços Públicos - que procure esclarecer e orientar a sociedade e o Poder Público 
em relação às atividades que atualmente devem ser prestadas não mais exclusivamente pelo Estado, mas sim sob sua fiscalização.

O progresso tecnológico, social e ambiental exige constantes mudanças no atuar estatal, sob pena de se tornar o Estado um imenso paquiderme obsoleto. Internet, manipulação genética, aquecimento global e todas as consequências desse novo caminhar da sociedade humana exigem, ao mesmo tempo, uma mudança de mentalidade e uma busca constante por novos conceitos e atitudes, visto que a incerteza jurídica é, o mais das vezes, origem e causa de uma série de conflitos.

A existência de uma "Carta dos Serviços Públicos" não sanará todas as dúvidas existentes relativas ao conceito da expressão serviços públicos, mas porá fim às incertezas jurídicas decorrentes da ausência de consenso. Tal documento, assim como seu similar comunitário, deverá permanecer em constante atualização, acompanhando, dessa forma, o desenvolvimento do conhecimento e das relações humanas e garantindo, com mais certeza e eficácia, os direitos fundamentais da pessoa humana assegurados pela Constituição da República Federativa do Brasil.

\section{Referências}

ARAGÃO, Alexandre Santos de. Direito dos Serviços Públicos. Rio de Janeiro: Forense, 2007.

BEZERRA, Helga Maria Sabóia. As transformações da noção de serviço público na União Européia: o serviço de interesse geral do Tratado de Lisboa, in Direito, Estado e Sociedade n.32, jan/jun 2008.

BRASIL. SUPREMO TRIBUNAL FEDERAL. ADPF $n^{\circ}$ 46/DF. Julgamento: 05/08/2009. Relator(a): Min. Marco Aurélio. Relator(a) p/ Acórdão: Min. Eros Grau. Órgão Julgador: Tribunal Pleno. Disponível em http://redir.stf.jus.br/paginador/paginador.jsp?docTP=AC\&doclD=608504.

CARVALHO FILHO, José dos Santos. Manual de Direito Administrativo. 21. ed. Rio de Janeiro: Lumen Juris, 2009.

DI PIETRO, Maria Sylvia Zanella. Direito Administrativo. 23. ed. São Paulo: Atlas, 2010.

EUROPA. O portal oficial da União Europeia, disponível no endereço http://europa.eu/index_pt.htm. 
Diretrizes para um conceito de Serviço Público: necessidade brasileira ou enclausuramento de uma concepção?

GROTTI, Dinorá Adelaide Musetti. O serviço público e a Constituição Brasileira de 1988. São Paulo: Malheiros, 2003.

JUSTEN FILHO, Marçal. Curso de Direito Administrativo. 3. ed. São Paulo: Saraiva, 2008.

MEDAUAR, Odete. Direito Administrativo Moderno. 12. ed. São Paulo: Revista dos Tribunais, 2008.

MEIRELLES, Hely Lopes. Direito Administrativo Brasileiro. 35. ed. São Paulo: Malheiros, 2009.

Tratados Consolidados e Carta dos Direitos Fundamentais. Disponíveis em: http://bookshop.europa.eu/is-bin/INTERSHOP.enfinity/WFS/EU-Bookshop-Site/pt_PT//EUR/ViewPublication-Start?PublicationKey=QC3209190.

Artigo recebido em 13/02/2012 e aprovado para publicação em 23/04/2012. 
